\title{
Radiofibrinogen Catabolism in Nephritis
}

\author{
E. N. WARDLE, D. N. S. KERR
}

British Medical fournal, 1975, 1, 489-491

\section{Summary}

A radiofibrinogen catabolism study performed on 40 patients with glomerulonephritis has shown increased fibrinogen catabolism in active immune-complex disorders.

\section{Introduction}

In various types of human glomerulonephritis fibrin may be shown to be present in the glomeruli by immunofluorescent techniques (Vassalli and McCluskey, 1971). It may occur both when antibody is produced against the glomerular basement membrane (Floyd et al., 1973) and in the nephritis caused by circulating antigen-antibody complexes (Dixon, 1968). Much emphasis has been placed on the leakage of fibrin into Bowman's space since this provokes the formation of epithelial crescents which impede glomerular filtration; these are associated with rapid progression of the nephritis. Such fibrin is due to extravascular leakage as in any inflammatory reaction and indicates an increased permeability of the basement membrane. Fibrin outside the capillary is no longer exposed to intravascular fibrinolysis and is more likely to persist and to be seen in renal biopsy samples. Theoretically, however, intravascular coagulation will accompany any form of active immune-complex disease since immune complexes or antibody bound to basement membrane initiate platelet damage (Wardle, 1972 a; Anderson et al., 1974).

Though fibrin deposition in the kidney is only the end result of a series of immunopathological insults (Dixon, 1968) intravascular coagulation contributes to the renal damage (Wardle, 1974) and the rate of fibrin deposition may be expected to reflect the activity of the disease. When intravascular coagulation is considerable it should be detectable as an increased turnover of intravascular fibrinogen. Radiofibrinogen turnover is measured simply and relatively inexpensively. It provides an attractive alternative to serial renal biopsies or multiple measurements of glomerular filtration as an indicator of disease activity in glomerulonephritis. In the comparable case of renal transplant rejection it normally shows an amelioration in the patient's condition at once (Wardle et al., 1974) and thus should be particularly valuable in assessing the response to treatment in nephritis. In a preliminary assessment of its suitability for this role we have measured radiofibrinogen catabolism in 40 patients with various forms of nephritis and tried to correlate the results with other evidence of disease activity.

\section{Methods}

Informed permission was obtained for each study, which was performed according to the principles of McFarlane (1963) with $50 \mu \mathrm{Ci}$ of ${ }^{125} \mathrm{I}$-fibrinogen from the Radiochemical centre, Amersham. Daily urine collections and plasma samples were counted as described (Wardle, $1972 \mathrm{~b}$ ). The log of the isotope counts of isolated washed

Wellcome Research Laboratories, Royal Victoria Infirmary, Newcastle upon Tyne NE1 4LP

E. N. WARDLE, M.B., M.R.C.P., Lecturer in Medicine (now at St. Peter's Hospital, Chertsey)

D. N. S. KERR, M.SC., F.R.C.P., Professor of Medicine

fibrinogen from duplicate $0.5-\mathrm{ml}$ samples of plasma was plotted against time and the lines were drawn by graphical resolution. Additionally all but four of the patients one with acute nephritis (case 1) and three with endocarditis described by Wardle and Floyd (1973) were passing enough urine to allow the measurement of fractional catabolic rates from urinary iodide excretion. In none of the patients was fibrinogen in the urine, as determined by counting the precipitable protein, large enough to account for an increased catabolic rate. Results were calculated as the percentage fractional catabolic rate, which is the percentage of the plasma fibrinogen pool catabolized daily (normal mode $21 \%$, range $15-28 \%$; Wardle, $1973 \mathrm{a}$ ).

Disease activity was assessed from the known clinical course of the patients after an initial renal biopsy, by the direction of change of the plasma creatinine, and, where appropriate, by changes in serum C3 and erythrocyte sedimentation rate, by a quantitative estimate of proteinuria and qualitative assessment of cell and cast excretion, and by attempted isolation of cryoglobulins (Meltzer and Franklin, 1969).

\section{Results}

Three case histories illustrate the use of the test.

Case 1, acute post-streptococcal interstitial nephritis.-A middleaged woman returned from India, where one month previously she had sustained insect bites which turned septic. She developed a cellulitis with rigors, for which she was given soluble penicillin, but she then developed erythema multiforme and acute nephritis. When her plasma urea reached $48 \mathrm{mmol} / \mathrm{l}(288 \mathrm{mg} / 100 \mathrm{ml})$ she was started on peritoneal dialysis. Her legs remained oedematous and infected and her blood pressure was $140 / 90 \mathrm{~mm} \mathrm{Hg}$. Urine microscopy showed red cells and red cell casts. The haemoglobin was $7.9 \mathrm{~g} / \mathrm{dl}$, white cell count $19.4 \times 10^{9} / 1$, serum C3 $0.98 \mathrm{~g} / \mathrm{l}$, and antistreptolysin $\mathrm{O}$ titre 500 Todd units. A radiofibrinogen catabolism study was begun. At that time her antistreptolysin $O$ titre rose to 2500 units, rheumatoid factor appeared at a titre of $1 / 16$, and mixed IgG-IgM cryoglobulins were detected in the serum. By the end of the first week of the test her creatinine clearance had risen from 5 to $25 \mathrm{ml} / \mathrm{min}$ and after a further week she was fully rehabilitated. Renal biopsy on the third day of the study showed tubulointerstitial nephritis but only minimal glomeruler proliferative changes. The radiofibrinogen study (fig. 1) showed a remarkable improvement in the catabolic rate around the seventh day, which, in fact, coincided with the improvement seen clinically.
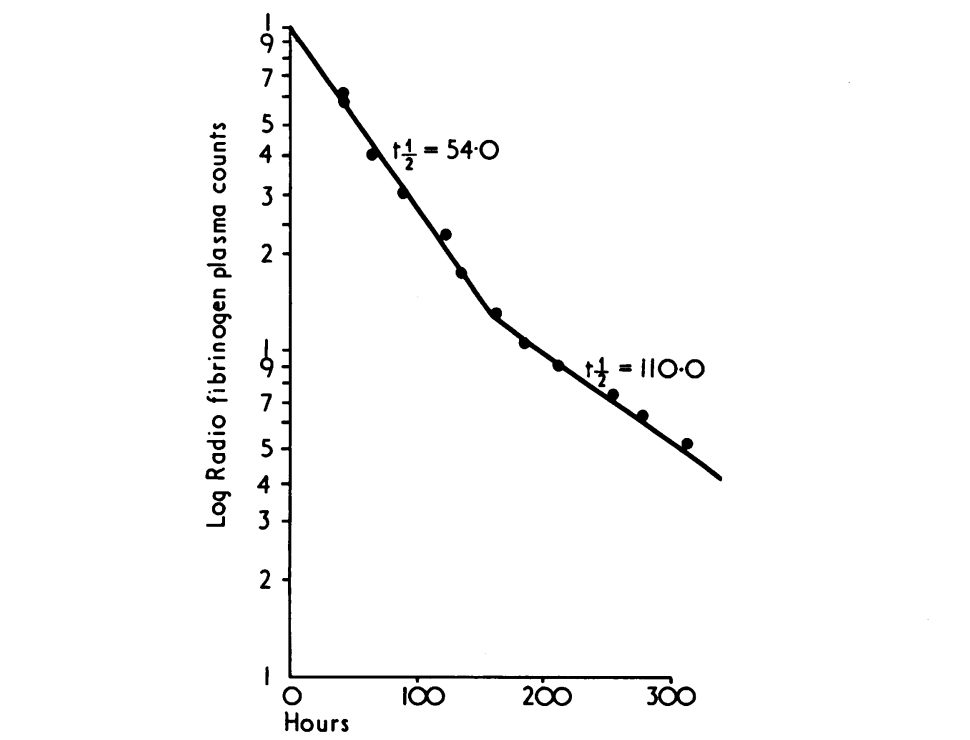

.


Case 2, Schönlein-Henoch purpura, $\alpha$-1-antitrypsin deficiency, and rapidly progressive nephritis in renal transplant.-An 18-year-old man presented in 1968 with repeated episodes of Henoch's purpura and one year later developed a nephrotic syndrome due to proliferative nephritis. A sister had died at age 12 with purpura and renal disease and another sister was also suffering from purpura. His $\alpha-1$-antitrypsin level was consistently $0.34 \mathrm{~g} / 1$ (normal $1.0 \mathrm{~g} / \mathrm{l}$ ). By 1971 he had progressed to terminal renal failure and required dialysis. In February 1972 he received a cadaver renal transplant but by December he had a rising serum creatinine level and heavy proteinuria. Biopsy showed severe glomerulonephritis with the formation of large epithelial crescents. His subsequent course justified the description "rapidly progressive nephritis" and he returned to haemodialysis. A radiofibrinogen study while his transplant was failing showed that the fibrinogen half life was shortened to 62 hours, and, accordingly, the fractional catabolic rate was raised to $42 \%$.

Case 3, scleroderma with renal changes and hypertension.-A student was found incidentally in the physiology class to have malignant hypertension. Three years earlier she had developed scleroderma. Her hypertension was resistent to conventional treatment and required diazoxide but her renal failure progressed. A radiofibrinogen study showed a shortened half life of 65 hours, a low percentage of fibrinogen remaining in the intravascular compartment (only 53\%), and a fractional catabolic rate of $48 \%$. Two months later she died of renal failure.

The fractional catabolic rates of the labelled fibrinogen in the various subcategories of nephritis are shown in fig. 2 . Patients judged to be in an inactive phase of their disease or who were recovering from a phase of acute nephritis are indicated by open circles. Patients with active disease are represented by black dots. In all, three patients had post-streptococcal nephritis, two of whom showed resolution during their study, and five had membranoproliferative glomerulonephritis (M.P.G.N.), among whom three with raised fibrinogen catabolic rates had hypocomplementaemia. There were also three patients with rapidly progressive nephritis who had increased catabolism. Three patients with systemic lupus erythematosus (S.L.E.) nephritis in an active phase had increased catabolism, and yet three with only minimal proteinuria and no red cells in the urine sediment had normal catabolic rates. The three patients with active subacute bacterial endocarditis (S.B.E.) and renal failure have already been described (Wardle and Floyd, 1973). One case of suspected endocarditis with stable but chronic renal failure has since been investigated. His fibrinogen catabolism was normal and there was no other evidence of disease activity though he did have severe chronic rheumatic heart disease.

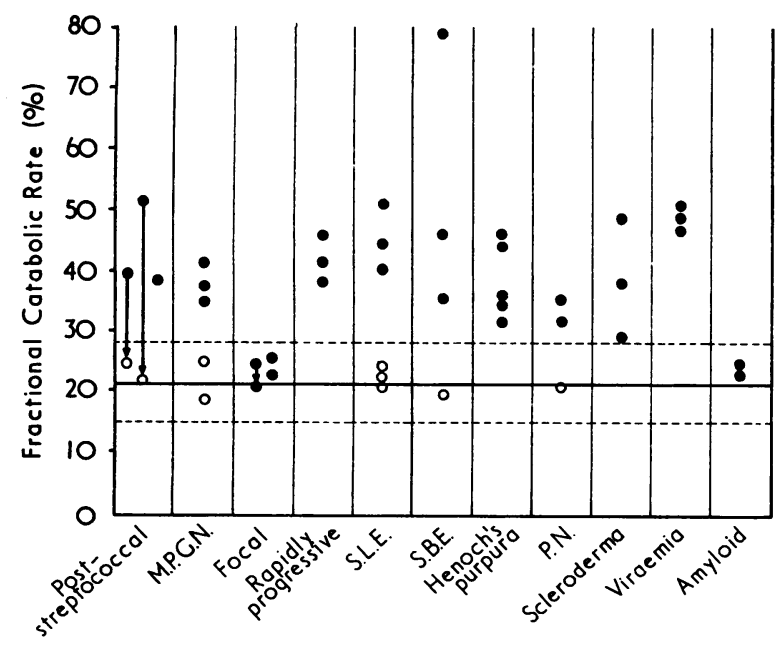

FIG. 2-Fractional catabolic rates of radiofibrinogen in various nephritic entities studied.

Also in fig. 2 are shown three patients who did not have nephritis but who had viraemia. All were renal transplant recipients who were not at the time in rejection. In two culture grew herpes simplex virus and in the other a diagnosis of cytomegalic virus infection was established by a rise in antibody titre. Five patients with Henoch's purpura, only two of whom had evident renal disease, had the highest fibrinogen catabolic rates. Three patients had scleroderma and three had polyarteritis (P.N.), of whom the two with raised catabolic rates had active disease.

Three patients with focal proliferative nephritis and the nephrotic syndrome had normal catabolic rates; one was studied twice. The normal catabolism in these patients emphasizes that proteinuria per se does not account for the raised catabolism found in other patients. This is confirmed by the normal results in two patients with amyloidosis and the nephrotic syndrome.

\section{Discussion}

There is no single index of the activity of nephritis against which the fractional catabolic rate can be compared. As in transplant rejection (Lopez et al., 1974) the diagnosis of activity is made intuitively from the computation of several variables. In assessing the disease activity in our patients, however, we concluded that radiofibrinogen catabolism does indeed reflect immune-complex disease activity provided that other forms of hypercatabolism can be excluded. The most important of these is bacteraemia (Wardle, 1972 b), and the present study shows that viraemia also must be excluded. Neither of these is common but other causes of generalized vascular damage such as the Schönlein-Henoch syndrome and scleroderma are also shown to cause fibrinogen hypercatabolism. The Schönlein-Henoch syndrome may be an immune-complex disease. The origin of scleroderma is in doubt but the diffuse endarteritis of the arterioles is evident.

Most patients with nephritis have disease confined to the kidneys, in which immune complexes are concentrated from the general circulation. Thus in these states the radiofibrinogen test promises to be a useful guide to activity and in the monitoring of therapy. Fibrinogen catabolism increases during acute and chronic rejection of a transplant (Wardle et al., 1975) and our study shows that it reflects the changing activity of several forms of nephritis. The test will be initially complementary to simpler estimates such as those of proteinuria, cast excretion, and changing serum creatinine while more data are built up by long-term prospective studies.

Possibly certain types of immune complex have a greater propensity than others for inducing low-grade intravascular coagulation. For example, in rabbits animals with precipitating antibody to bovine serum albumin antigen are those that develop intravascular coagulation and evidence of complement consumption on antigen challenge (Wardle, $1973 \mathrm{~b}$ ). It might be expected that the occurrence of rheumatoid factor, which in general implies the formation of larger antigen-antibody complexes (Tesar and Schmid, 1970). would be associated with intravascular coagulation. Takeda (1965), however, in a small series reported normal fibrinogen catabolism in patients with rheumatoid arthritis; apparently, however, patients with vasculitis were not studied.

Intravascular fibrin deposition has been monitored by following the changes in serum and urinary fibrin degradation products. These, however, cannot adequately reflect a dynamic situation, and urinary losses are partly a reflection of increased permeability of the basement membrane. We suggest that the radiofibrinogen study will prove to be a better index of intrarenal coagulation. Its value appears to depend on the normal high renal blood flow. The test is simple and less expensive than more sophisticated measures of fibrin degradation products. We therefore forsee a major role in monitoring the response to treatment in the more severe forms of nephritis. 
This work was supported by the Scientific and Research Committee of the Royal Infirmary, Newcastle.

Requests for reprints should be addressed to Dr. D. N. S. Kerr.

\section{References}

Anderson, M., Floyd, M., and Wardle, E. N. (1974). Kidney International. Submitted for publication.

Dixon, F. J. (1968). American fournal of Medicine, 44, 493.

Floyd, M., Shenton, B., and Swinney, J. (1973). British fournal of Experimental Pathology, 54,615 .

Lopez, C. et al. (1974). American fournal of Medicine, 56, 280.
McFarlane, A. S. (1963). Fournal of Clinical Investigation, 42, 346. Meltzer, M., and Franklin, E. C. (1969). American fournal of Medicine, 40,828 .

Tesar, J. T., and Schmid, F. R. (1970). Fournal of Immunology, 105, 1206 Takeda, Y. (1965). Fournal of Laboratory and Clinical Medicine, 1, 66.

Vassalli, P., and McCluskey, R. T. (1971). Advances in Nephrology, vol. 1, p. 47. Chicago, Year Book Medical Publishers.

Wardle, E. N. (1972 a). Fournal of the Royal College of Physicians, 7, 5.

Wardle, E. N. (1972 b). Scandinavian fournal of Infectious Diseases, 4, 155

Wardle, E. N. (1973 a). Quarterly Fournal of Medicine, 165, 205.

Wardle, E. N. (1973 b). Clinical Science and Molecular Medicine, 45, 35.

Wardle, E. N. (1973 b). Clinical Science and Molecu

Wardle, E. N., and Floyd, M. (1973). British Medical fournal, 3, 255.

Wardle, E. N., Uldall, P. R., and Swinney, J. (1975). Transplantation. In press.

\title{
Haematemesis: A New Syndrome?
}

\author{
A. T. R. AXON, A. CLARKE
}

British Medical fournal, 1975, 1, 491-492

\section{Summary}

Three patients presented with symptoms suggesting a Mallory-Weiss tear. Endoscopy showed a localized, clearly demarcated area of bright red mucosa near the gastro-oesophageal junction; this was thought to have arisen by retrograde intussusception of the stomach during vomiting or retching and may have caused the haemorrhage.

\section{Introduction}

Since 1929, when Mallory and Weiss described gastrointestinal bleeding from gastric tears, several papers (Dobbins, 1963; Freeark et al., 1964; Holmes, 1966) have drawn attention to the frequency with which vomiting or retching may induce haemorrhage. The increasing use of early endoscopy in patients who are bleeding has shown that these lesions are even more common than was previously thought (St. John et al., 1974). The advantage of early endoscopy is that mucosal lesions, invisible on $x$-ray films, may be readily seen. Most papers have described longitudinal tears in the cardia which may extend into the oesophagus. Delumeau et al. (1972), however, described three patients in whom the lesions were atypical. We have recently seen three patients with a history suggestive of a Mallory-Weiss tear but who at endoscopy had a different but characteristic lesion at the cardia.

\section{Case 1}

A 41-year-old labourer was brought to the casualty department by the police in February 1974. He was too drunk to give a history but it appeared that while being questioned at the police station he had vomited blood. While in the casualty department he vomited coffee grounds. Four years previously a vagotomy and pyloroplasty had been performed for a perforated duodenal ulcer. He was a heavy drinker and had been admitted drunk to the casualty department on several occasions. His pulse rate was $80 / \mathrm{min}$ and his blood pressure

St. Thomas's Hospital, London SE1 7EH

A. T. R. AXON, M.D., M.R.C.P., Senior Registrar

Queen Alexandra Military Hospital, London SW1P 4RF

A. CLARKE, M.B., M.R.C.P., Senior Specialist in Medicine
$120 / 70 \mathrm{~mm} \mathrm{Hg}$. There was an abdominal scar. No melaena was found on rectal examination.

Next day endoscopy was carried out with an Olympus GIFD and JFB. The patient began to retch when the endoscope was inserted and stomach mucosa was seen to be forcibly projected up through the gastro-oesophageal opening. The prolapsed mucosa was bright red, and when the retching had stopped an angry red ring of mucosa was seen which encircled the upper end of the stomach. It had clearly defined edges and the appearances were those of an acute gastritis with severe inflammation. No other abnormality was seen apart from the changes of pyloroplasty.

\section{Case 2}

A 23-year-old warehouseman at a spirits firm was admitted to hospital in June 1974 complaining of left-sided abdominal pain for six hours. For four or five years he had been drinking about two bottles of spirits daily and had had several similar episodes of abdominal pain which had usually followed more extensive drinking bouts. The pain was colicky and tended to be relieved to some extent by vomiting. On this occasion, after drinking a bottle of whisky he developed abdominal pain and vomited normally several times but then had a haematemesis of about 0.51 . His pulse was $110 / \mathrm{min}$ and his blood pressure $110 / 85 \mathrm{~mm} \mathrm{Hg}$. There was moderate tenderness in the left iliac fossa. Rectal examination showed no melaena. He was thought to have sustained a Mallory-Weiss tear.

Twenty-four hours after the haematemesis endoscopy with an Olympus GIFD2 showed a localized area of bright, angry erythema in the upper part of the anterior wall of the stomach just below the oesophagogastric junction. The erythematous area was about $3 \mathrm{~cm}$ in diameter and had a clearly demarcated edge; the centre was superficially ulcerated. No other lesion was present in the oesophagus, stomach, or duodenum.

\section{Case 3}

A 35-year-old caretaker had a long history of repeated bouts of retching and abdominal pain often followed by small haematemeses. In 1972 he had a vagotomy and pyloroplasty for a duodenal ulcer. He admitted to smoking 25 cigarettes and drinking four bottles of beer a day.

In April 1974 he was referred for endoscopy 48 hours after a further bout of vomiting which culminated in a minor haematemesis. During the insertion of the endoscope, an Olympus GIFD2, he began to retch; bright red gastric mucosa was seen to prolapse into the lower oesophagus. When retching had stopped inspection of the stomach showed a clearly demarcated haemorrhagic area about $3 \mathrm{~cm}$ in diameter immediately below the gastro-oesophageal junction on the lesser curve. There was no obvious bleeding site or ulceration and no other abnormality was seen. Several biopsy specimens from the lesion showed mild oedema of the lamina propria only. 